logos_i_ethos_2018_1_(47), s. 153-179

DOI: http://dx.doi.org/10.15633/lie.2555

Denis Larrivee PhD

Loyola University Chicago, USA

Luis Echarte MD

Mind and Brain Institute, School of Medicine, University of Navarra,

Pamplona, SPAIN

\title{
Framing Neuroethical Praxis: Wojtyła's Metaphysical Subject and its Modernist Cartesian Variants
}

\section{Introduction: \\ The Metaphysical Subject as a Corporal Reality}

Karol Wojtyła approached ethics through an enduring interest in man's fundamentally personalist nature. ${ }^{1}$ His ethical study had two objectives: to characterize the personalist subject as an agent of ethical activity and as an end for the pursuit of the good, that is, as a value contingent locus. His interest in validating ethical praxis thus fell outside the pragmatic question of the manner of its practice, meaning that it fell within a sphere more properly characterized as metaethical.

Although Wojtyła distinguished both objectives conceptually, he recognized that this distinction did not imply their mutual independence. Linking these two, he argued, was the experience of morality that manifested itself in action. Understood as the ground for value contingency
Denis Larrivee - is a Visiting Scholar at Loyola University Chicago, and holds memberships in the International Association of Catholic Bioethicists and International Neuroethics Society. He is the author of some fifty papers and the current editor of a volume on brain computer interfacing and global neural dynamics.

Luis Echarte - is a professor in the Mind and Brain Institute, School of Medicine, University of Navarra, Pamplona, Spain.

1 Cf. K. Wojtyła, Man in the Field of Responsibility, Vatican City 1991, passim. 
in the person, the capacity for the performance of the 'good' thereby established the personal agent as a value locus.

The reality of the person inheres in morality, that morality is a thoroughly specific and connatural reality with respect to the person - with respect precisely to the person and only to the person [...] man as a man, becomes good or evil through the act. ${ }^{2}$

As a metaethical object for the evolution of ethical praxis, thus, the capacity for morality validated the wholly referential status of the person.

It was in view of this referential status, that is, as a meta domain that defined and determined ethical praxis in inquiry and practice, that the objective reality of the person could be normatively qualified. Holub ${ }^{3}$ points out that in Wojtyła's specific exploration this reality was constituted in the phenomenal subject, that is, in the specific sphere of reality that defined the unique interiority and operativity of the individual. Wojtyła's emphasis on the phenomenal subject, accordingly, is reminiscent of distinctively modern elements such as consciousness and self awareness and a performative dimension that originates from within a personal 'someone,' hence belonging to no other. However, by invoking a Thomistic metaphysical deduction, he goes beyond this exterior and phenomenal expression to forge a link to an inner and integral unity, a 'humanum suppositum, for which the expressed dimension is only one manifestation. By this integral unity he meant a metaphysical subjectivity that grounded the objective, epistemological reality of the personalist subject. Karol Wojtyła's personalism thus drew, as he claimed, from a philosophy of 'genuinely metaphysical range' ${ }^{3}$ where the person 'constitutes a privileged locus for the encounter with being, and so with metaphysical inquiry.'

${ }^{2}$ K. Wojtyła, Man in the Field of Responsibility, op. cit., p. 17.

3 Cf. G. Holub, The Human Subject and its Interiority: Karol Wojtyła and the Crisis in Philosophical Anthropology, "Quien" 4 (2016), p. 47-66.

${ }^{4}$ Cf. G. Holub, The Human Subject and its Interiority..., op. cit., p. 47-66. 
For ethical praxis this conception is significant in linking the subject's dynamical operativity not solely, or merely, to a collection of phenomenal events, but to an integral and unique subject. Accordingly, it is fundamentally constitutive for ethics. What Wojtyła offers, therefore, is a metaphysical justification for ethical praxis, and an exploration of those modalities that would be normatively qualified through this metaphysical link. Burgos has specifically identified the object of Wojtyła's exploration with personal subjectivity:

what Wojtyła is searching for is a reelaboration of Thomistic gnoseology that considers the advances of modernity and mostly the possibility offered by the phenomenology of directly accessing the subjectivity of the person. ${ }^{5}$

Such a characterization, indeed, reflects the phenomenal emphasis of Wojtyła's personalist exploration; however, it nonetheless fails to consider other manifestations that are metaphysically anchored, since his metaphysical subject is neither purely phenomenological nor wholly structured by the phenomenal dimension. In fact, the humanum suppositum both extends and confirms the possibility for exploring a multiplicity of other modalities that may constitute its predicates, and that do not rely on such a unimodal manifestation. This extension allows Wojtyła to move beyond the purely phenomenological to other dimensions of the subject.

Crucially, as Holub points out, the humanum suppositum bridges and integrates alternative manifestations that are constitutively present, thereby subordinating these also within the ethical sphere.

The subject is not a sequence or stream of psycho-physical events taking place in the human individual. Rather it must be characterized by a metaphysical structure, which precedes all acts and happenings. ${ }^{6}$

5 Cf. J. M. Burgos, The Method of Karol Wojtyła: A Way Between Phenomenology, Personalism and Metaphysics, "Analecta Husserliana" 104 (2009), p. 110.

6 J. M. Burgos, The Method of Karol Wojtyła..., op. cit., p. 110. 
The metaphysical structure therefore also anchors physical attributes of the person, especially of the nervous system, which is widely invoked as the physical substrate for the phenomenal subject, and where questions of praxis have been classed in the domain of neuroethics. ${ }^{7}$ By identifying the subject as a metaethical principle, that is, as a value contingent object, he thus extends, by virtue of the metaphysical unity of the person, value to all those attributes that constitute the subject. Indeed, this metaphysical inference enables Wojtyła to caution in Veritatis Splendor 'against a manipulation of corporeity which would alter its human meaning [...]' on grounds that the ' $[\ldots]$ nature of the human person is in the unity of body and soul [...] that stand and fall together $[\ldots]^{\prime 8}$ a clear indication that he regarded the corporal manifestation to be subsumed within the metaphysical concept of the suppositum, which thus acts to validate an ethical praxis within the corporal sphere. Indeed, Wojtyła's recognition of the fundamental participation of the corpus in the integral unity of the human is also evident in his opus Man and Woman: He Created Them: A Theology of the Body, ${ }^{9}$ a position expressed in more nascent form in Montini's Humanae Vitae ${ }^{10}$ that is probative for technological interventions circumventing the generation of biological life. In the logic of the metaphysical argument the suppositum can be expected, therefore, to anchor neuroethical praxis concerned with the impact of neural intervention on the specifically human meaning of life.

The utility of the metaphysical dimension to neuroethics thus emerges from its link to the specifically corporal contribution made to the unity of the person, that is, as a physical structure that is enabling to a human

7 Cf. P. Reiner, The Rise in Neuroessentialism, in: The Oxford Handbook of Neuroethics, eds. J. Iles, B. Sahakian, Oxford 2011, p. 161-176; N. Levy, Neuroethics and the Extended Mind, in: The Oxford Handbook of Neuroethics, op. cit., p. 285-294; A. Roskies, Mental Alchemy, http://www.theneuroethicsblog.com/2016/08/mental-alchemy_23.html (23.08.2016).

8 Cf. John Paul II, Pope, The Splendor of Truth = Veritatis Splendor: Encyclical Letter, Boston 1993, no. 50 .

9 Cf. John Paul II, Pope, Man and Woman: He Created Them. A Theology of the Body, trans. M. Waldstein, Boston 2006.

10 Cf. Paul VI, Pope, Humanae Vitae. Encyclical Letter, Vatican City 1968. 
ontological, subjective and integrative order. As such its utility to neuroethical praxis devolves from the fundamental participation of the corporal manifestation in structuring the ontological unity of the individual. By extension, this corporal contribution may be used to assess the validity of metaphysical presuppositions of other, modern neuroethical variants. These points are taken up in the following discussion.

\section{The Humanum Suppositum and Ontological Integration}

As a metaphysical structure that precedes all acts that are its manifestation the humanum suppositum enters into every physical act, sustaining it by virtue of making present an integral order that it confers on the person. ${ }^{11}$ Through its entry into these acts, therefore, it is also a dynamical participant in them. What is of even greater significance is that by entering into these various dimensions, the metaphysical subject shapes them according to an expressed personal subjectivity; hence, it also molds the neural architecture, which expresses this manifestation corporally. Wojtyła is therefore able to claim that the human body

has been created to transfer into the visible reality of the world the mystery hidden from eternity in God, and thus to be a sign of it $^{12}$

that is, the human body physically manifests an originary, metaphysical reality subsisting in a unitary and personalist subjectivity that is ordered to the performance of the good. Value contingency in the metaphysical and personalist subject is thereby linked to the corporal form that manifests it.

11 Cf. G. Holub, The Human Subject and its Interiority..., op. cit., p. 47-66.

12 Cf. John Paul II, Pope, Man and Woman..., op. cit., passim. 


\subsection{Transference of the Metaphysical Subject into Visible Reality}

For a neuroethical praxis, the humanum suppositum is a reality accessed first through the phenomenal subject's objective, corporal manifestation, ${ }^{13}$ that is, it is first understood at the epistemological level of the phenomenal subject, and only then at the metaphysical one. Significantly, its dependence on the epistemological level does not imply its absence in the order of being. If so, the phenomenal subject would be reduced to one manifestation among a collective, consisting of a variety of dynamisms, and not linked to an overall unity. The epistemological understanding of the subject is thus revelatory for the Wojtyłan metaphysical conception, which thereby situates within its sphere the corporal form of the neural dynamic. This dynamic, consequently, is understood to be shaped according to the pattern of the humanum suppositum to yield, that is, to transfer into physical reality, the uniquely human subject; hence, it identifies the neural dynamic as a normative terrain to be "charted" for probative concerns.

Metaphysically, the humanum suppositum is seen, first, in its evocation of the human entity, that is, the neural architecture is unified operatively. As a metaphysical prior of the phenomenal subject, therefore, this evocation elicits the adoption by the corporal form of an organizational order characterized by operational confinement and underpinned by a systemic and dynamical configuration that is needed for autonomous living. This unitary dynamic, for instance, is a fundamental feature acted upon by evolution. As evolutionary philosopher Cliff Hooker points out ${ }^{14}$ it is the activity of the whole organism that interacts with the environment and the whole organism that is molded by evolutionary pressures, which thereby acquires behaviors that are good for it. Likewise, such self initiated actions presuppose a holistic organizational order, that is, a source for their emergence. Philosophers of biology Maturana and

13 Cf. G. Holub, The Human Subject and its Interiority..., op. cit., p. 58.

14 Cf. C. Hooker, Interaction and Bio-cognitive Order, "Synthese" 166 (2008), p. 513-546. 
Varela ${ }^{15}$ and Moreno and Mossio ${ }^{16}$ propose, in consequence, that the autopoetic capacity of living organisms - understood as the organismal ability to produce themselves - can be present only if organisms are purposed to autonomous existence as integrated, operational, and topologically distinct wholes. They evidence this purposing in pointing to the recursive restructuring used to sustain autonomy in the face of ongoing thermodynamic constraints. Autonomy, thereby, constitutes a capacity for existence that can only be exercised as an entity.

However, since autonomy is also a condition of state, it can be exercised only through certain dispositions, which act, therefore, as qualifiers for autonomous entities. For humans, these include self governance, agency, and a behavioral repertoire enabling a capacity to resist constraints imposed by one's environment. These dispositional qualifiers therefore evidence, secondly, the contribution of the humanum suppositum to the ontological shaping of the phenomenal subject and the neural architecture that sustains it. The consolidation of a neural architecture underlying the self percept, for example, illustrates a metaphysical conformity of the whole ontological dynamic to the unity transcendental. Contingent properties that emerge from the neural architecture, including those that contribute to the phenomenal subject, such as reasoning, consciousness, agency, and identity, predicate from the self, that is, they display independent manifestations and so possess neural circuitries distinguishable from that of the self, though nonetheless subsumed to its oversight.

The subject's corporal manifestation is thus not autonomously determined but is shaped by an extrinsic order that is determinative for its expression. Indeed, the natural biological order shares this subordination to an immaterial prior, an observation often used to explain why living processes assume unique configurations rather than merely how

15 Cf. H. R. Maturana, F. Varela, De maquinas y seres vivos. Autopoiesis: La organizacion de lo vivo, Santiago de Chile 1979.

16 Cf. A. Moreno, M. Mossio, Biological Autonomy: a Philosophical and Theoretical Enquiry, Berlin 2015. 
they do so, that is, explananda classed as design principles. ${ }^{17}$ Such principles are useful for explaining the metaphysical contribution to cognition. They explain, in the first place, why only certain organizational arrangements enable cognitive operation, that is, they explicate the need for cognition to adopt a particular order. Kelso, ${ }^{18}$ in a prescient commentary, remarks that while nature's forms are abundant, its principles are few, and carefully preserved, meaning that the design of living systems is neither arbitrary nor haphazard. Indeed, numerous studies now document the adoption of such design principles in the construction of complex biological systems, an illustration that only certain preferred operational forms can be used, and so are, necessarily, widely adopted. For example, gene regulation networks in cells are constructed of a handful of recurring circuit elements, each of which can carry out specific dynamical functions autonomously, ${ }^{19}$ or, similarly, cases of cellular networks that resonate in unison in a performance space. ${ }^{20}$ What these studies emphasize is the apparent universality of the deployment of successful designs. Design principles, accordingly, are instantiated by living organisms because they constitute valid principles of operation on which the dynamic order of living organisms needs to be grounded for successful performance.

By extension, such principles help to explain why cognition needs to exhibit a unified operation and why its qualifying properties, in turn, need to be configured as predicates of an autonomously directed entity. The instantiation of attractor motifs in neural network operation, for example, constitutes a revealing design feature for brain activity since it shows that such motifs are linked to the system wide, neural network

17 Cf. P. Braillard, Systems Biology and the Mechanistic Framework, "History and Philosophy of the Life Sciences" 32 (2010) no. 1, p. 43-62.

18 Cf. S. Kelso, Dynamic Patterns: The Self-Organization of Brain and Behavior, Cambridge 1995.

19 Cf. U. Alon, An Introduction to Systems Biology, Design Principles of Biological Circuits, Boca Raton 2007, p. 1.

20 Cf. Y. Hart, Y. Antebi, A. Mayo, N. Friedman, U. Alon, Design Principles of Cell Circuits with Paradoxical Components, "Proceedings of the National Academy of Sciences of the United States of America” 109 (2012) no. 21, p. 8346-8351. 
activity of the brain; hence, it reveals the presence of constraints that subsume these motifs within a holistic form. Friston makes the pertinent comment here that

our exchanges with our environment are constrained to an exquisite degree by local and global brain dynamics and that these dynamics have been carefully crafted by evolution, neurodevelopment, and experience to optimize behavior. ${ }^{21}$

A significant issue raised by these explanations is then how the biological order depends on such extrinsic influences, that is, how metaphysical constraints influence the materially manifested form seen in the neural architecture. Explanatory accounts for cognitive order, accordingly, need to be concerned with the nature of this relationship, both its origin and the manner by which constraints on the instantiated order are imposed. Michael Morange ${ }^{22}$ offers one explanation, arguing that the imposition of such constraints is due to physical laws that establish limits on outcome. He points, for instance, to allometric scaling laws that establish physical dependencies between different properties of an organism such as metabolism and size. Yet Morange's physical explanation begs the question for the existence of such a physical ordering; thus it cannot be the sole basis on which to explain the why question for the order of neural operation. This explanatory insufficiency can be seen, for instance, in Yi et al's study of integral feed back, which shows that only this type of recurrency can achieve resonance. ${ }^{23}$ While Yi's study demonstrates a physical and causal effect mediated by one element on another, it also shows that the effectiveness of this operation is not itself solely a consequence of a physical dimension. What is critical here is the presence of feedback connections and an organized composition

21 Cf. K. Friston, Free Energy and Global Dynamics, in: Principles of Brain Dynamics, eds. M. I. Rabinovich, K. J. Friston, P. Varona, Boston 2013, p. 269-292.

22 Cf. M. Morange, Les Secrets du Vivant: Contre la Pensee unique en Biologie, Paris 2005.

${ }^{23}$ Cf. T. M. Yi et al., Robust Perfect Adaptation in Bacterial Chemotaxis Through Integral Feedback Control, "Proceedings of the National Academy of Sciences of the United States of America" 97 (2000), p. 4649-4653. 
in which the elements are circularly arranged. These latter features are abstract, that is, they are non-physical characteristics that nevertheless have a bearing on performance. By extension and for this reason, recurrency in neural network operation, among other cognitive features, has at once both a physical and an immaterial dimension.

Non-physical influences are also evidenced in the large scale formal order of cognition, like the brain's integrated performance amidst the complexity of the neural architecture, as well as in small scale order, like the dynamical attractors mentioned by Friston. Because the material order is subsumed to these immaterial features the latter can be regarded as a supraphysical influence effecting their material instantiation. The act of instantiation thus means that the material dimension, in a formally causal sense, is subordinate to an influence that is universally pertinent, exteriorized, and supraphysical and so is determinative for the adopted topology. ${ }^{24}$

It is in the context of this supraphysical influence on cognition that Wojtyła's introduction of the humanum suppositum is relevant. That is, it is only through the metaphysical order that the neural architecture is shaped according to the ontological form of the phenomenal subject. This shaping is not merely a matter of the neural architecture adopting one among a variety of forms, that is, the adoption of an arbitrary hylomorphic expression, but it is the specific acquisition in the epistemological order of the phenomenal subject, as Wojtyła points out. This metaphysical association thus anchors the objective reality of the phenomenal subject in an immaterial one that is ontologically generative. Indeed, the phenomenal subject shares with the humanum suppositum its relational orientation toward being, seen, for example, in the evolutionary trend toward knowledge acquisition and dynamical freedom. ${ }^{25}$

24 Cf. C. Gillett, Reduction and Emergence in Science and Philosophy, Cambridge 2016, p. 2.

25 Cf. N. Clark, Person and Being, Marquette 1993, p. 36. 


\subsection{Ontology and Integration: the Physical Object of Neuroethical Praxis}

From Wojtyła's metaphysical conception, accordingly, there emerges the key issue for neuroethical praxis, the manner by which the suppositum physically structures the personalist subject, both in the unification of its dynamical operativity and in its generation of an ontological order. Inferences about the contribution of the suppositum to the physical ordering of the personal subject must begin, then, with the a priori recognition of the dynamic reality that integrates and unifies the personalist subject, that is, the metaphysical ground that structures the objective reality that is manifested through the corporal entity. By contrast, the absence of such a unifying dynamic, that is, the specific neglect of an a priori metaphysical structure, seen, for example, in cognitive ontology accounts, ${ }^{26}$ otherwise leaves neuroethical praxis inchoate without either a contingent locus for value or a medium for conducting it; hence, it nullifies neuroethics as a normative science grounded in a unifying dynamic. While ethical theories of phenomenal connectivity are yet invoked (Parfit), they run counter to the observable manifestation of purposeful unity noted by Kant, empirically manifest in evolution, and, increasingly, detected in the neurosciences. It is, therefore, by grounding the corporal contribution to the manifestation of the personalist subject in a metaphysically unified structure that a Wojtyłan approach can specifically contribute to an ethical praxis on biomanipulations of the neural architecture and its operativity. From these considerations it is apparent that metaphysical conceptions on configured entities are key to understanding such normative concerns, that is, they are the key metaethical dimension needed for the evolution of praxis in neuroethics.

Nonetheless, due to the empirical nature of assessments on a specifically corporal contribution to ontology, their clarification of neural design remains ongoing and needed for the proper evolution and refinement of ethical praxis. This is to say, that empirical and philosophical 
study on the form of the neural architecture is an essential clarification of the working out of the metaphysical subject in its material dimension. This clarification encompasses two aspects: the mediation of 1) ontological primacy in the manifestation of the personalist subject and 2) the operational integration of the corporal entity. It is in the former that contemporary neuroscience can inform the identification and characterization of the corporal features needed to manifest the personalist subject but it is only in the second that we can delimit their role to its holistic expression. In fact, existing evidence suggests their mutual interdependency.

Through this dialectic it is possible to see how Wojtyła's conception assists in clarifying the specifically corporal role that the neural architecture exercises in structuring the phenomenal subject. In identifying the ontological and integrative, neural attributes it becomes possible, in particular, to identify the corporal features of the neuroarchitecture that qualify as a normative terrain; hence, their determination can be expected to facilitate the construction of neuroethical norms for which a 'corporal manipulation - directed either to neurorehabilitation or other purposes - that alters its specifically human meaning' would be probative. They are, nonetheless, subject to continuing conceptual and empirical refinement.

As an ongoing revelation, this neural contribution can only be intimated here, but existing studies offer a portrait consilient with Wojtyła's metaphysical conception. These studies begin to show, notably, that the performative integration of the corpus is mediated ontologically by what is often referred to as a self construct, in a manner conceptually analogous and illustrative of the Wojtyłan humanum suppositum. Significantly, the instantiation of self circuitries very likely occurs in an evolutionary and performative context; hence, metaphysical constraints effecting their embedding shape self circuitries in the context of the integration of both brain and body; ${ }^{27}$ hence, value contingencies rest in the whole human

27 Cf. C. Hooker, Interaction and Bio-cognitive Order, op. cit., p. 513-546; L. Smith, Stability and Flexibility in Development, in: Toward a Unified Theory of Development, eds. J. P. Spencer, M. S. 
entity, and not solely, though predominantly, in the neural processes used to evoke its perceptual realization. What is of value, then, is the ontological and systemic organization of the human in his embodied context; specifically, the neural architecture is privileged through its role in mediating this integration.

In keeping with much evidence the body is intrinsically involved in assisting the brain in constructing the manifestation of the subject. ${ }^{28}$ A hierarchical layering of dynamical neural elements is framed by the exchange between the two that involves the reciprocal and mutually dependent flow of information effected between brain regions, like that, for example, of the hippocampus and the distributed sensory and motor neural network that lies beyond the brain. This relationship is necessarily constrained by the dynamical nature of brain activity, which is continuous, and the need for stability, which remains the cornerstone of the brain's dynamical operation. Hence, built into the dynamical layering is a predisposition to create coherent and unified structures that can carry out the grander tasks of the neural architecture.

Interestingly, evidence for such coherence has come from studies that explore the lack of certain cognitive capacities rather than their presence, as, for example, the demonstration of perseveration in infants. ${ }^{29}$ Such studies reveal, thereby, the need for a holistic organization, since in its absence a dynamical unity cannot be exercised. In the case of infant perseveration, for instance, cognitive processing of the body's disposition in space is needed to relate the individual to the events of the world. This is to say that the whole body is needed to create a stable and coherent image that can be interactively and cognitively positioned in motor planning. Indeed, identity and self awareness both appear to be linked to this embodied dimension. ${ }^{30}$ Intentional acts in developing infants to either stand upright or to crawl, for instance, effect a differential brain map-

C. Thomas, J. L. McClelland, Oxford 2009, p. 67-85; D. Corbetta, Brain, Body, and Mind: Lessons from Infant Motor Development, in: Toward a Unified Theory of Development, op. cit., p. 51-56.

28 Cf. S. Gallagher, How the Body Shapes the Mind, Oxford 2005, p. 5.

29 Cf. L. Smith, Stability and Flexibility in Development, op. cit., p. 73.

30 Cf. D. Corbetta, Brain, Body, and Mind..., op. cit., p. 51-56. 
ping depending on the performative act intended, such as the acquisition of bimanual skills with the corresponding coupling of sensori-motor areas. This observation reveals that task performance is related to the linkage made between the goal and the individual for whom the goal is intended, which is to say that intentional performance requires a stable representation of the individual that can be cognitively perceived and physically mobilized as a whole. Such examples, show a needed, holistic and bodily contextualized, self representation for performance that can be employed in a wide variety of interactive and dynamic circumstances. Hence, they are ethically significant for beginning a process of charting unifying corporal features, that is, neural correlates, which outline a neuroethical terrain.

\section{Metaphysical Presuppositions in Modern Neuroethics}

Significantly, most modern meta neuroethical approaches, with notable exceptions, acknowledge the individual to be a central value locus, as does Wojtyła's ethical personalism. Nonetheless, differences among metaphysical presuppositions about the individual significantly affect the understanding of value contingency, and the praxis that devolves from them. Meta-ethical principles that shape modern neuroethical praxis are therefore strongly influenced by their metaphysical understanding of the world, which in turn determines value contingency and ethical praxis. These deviate significantly from a Wojtyłan personalist ethics that is oriented to preserving the human meaning of the corpus.

Given the plurality of a priori, metaphysical presuppositions that influence modern neuroethics, their reconciliation with Wojtyła's humanum suppositum can be expected to be partial and in cases unattainable. Nonetheless, such modern meta-principles are heavily influenced by the Cartesian understanding of reality, itself a derivative of Aristotelian and Thomistic syntheses, which is presupposed in Wojtyła's suppositum. Hence, these modern presuppositions share a conceptual foundation with Aristotelian metaphysics, the dominant conception of the natural world, which is characterized by individuated entities that are qualified 
by their predicates. ${ }^{31}$ While Whiteheadian process metaphysics has been invoked in this century to explain temporally extended, processional events, increasingly the recognition that processional events themselves comprise operational features of larger dynamical entities is accepted, that is, their diachronic temporality is subsumed within a synchronic and dynamical organizational order that is characteristic of living organisms, particularly of their neural operativity. ${ }^{32}$ The increased acceptance of this conception ${ }^{33}$ exposes lacunae in underlying premises on ontic adequacy that have come to challenge Cartesian metaphyics and that are likely to mold new formulations that conciliate better with a broader and a more synthetic conceptual approach that has traditionally been associated with Aristotelian and Thomistic metaphysics. This is to say that the epistemological observation of the neural architecture may itself offer a bridge for revising Cartesian presuppositions that mark modern neuroethics and that may serve as nuclei of a neuroethical 'rapprochment.' Indeed, the link between reality and conceptual understanding recapitulates the classical Thomistic and pre-Vicoan formulation of the truth transcendental,

'Veritas est adequatio rei et intellectus' that is, 'truth is the correspondence of the mind to reality. ${ }^{34}$

\subsection{Being and the Phenomenal subject in Modern Neuroethics}

Descartes' res cogitans is generally regarded as the first conception of the isolated subject, an entity that performs cognitive acts like thinking, willing, or feeling. ${ }^{35}$ This subject is capable of cognition independent

${ }^{31}$ Cf. M. Esfeld, Quantum Enganglement and a Metaphysics of Relations, "Studies History Philosophy Modern Physics” 35 (2004), p. 601-617.

32 Cf. W. Bechtel, Explicating Top-down Causation Using Networks and Dynamics, Oxford 2017.

33 Cf. R. Laughlin, Physics, Emergence, and the Connectome, "Neuron" 83 (2014) no. 6, p. 1253-1255.

34 D. R. Lemieux, She is Our Response, New Bedford, MA 2011.

${ }^{35}$ Cf. G. Holub, The Human Subject and its Interiority..., op. cit., p. 47-66. 
of its association with a body, that is, it is distinguished by its purely phenomenal structure. Despite its bodily independence it nevertheless can know itself uniquely and differentiate itself from all other thinking and willing entities. In creating this subject Descartes effected a metaphysical divorce, separating immaterial from material reality. Heidegger points out that by taking the ground of reality to be the autonomous subject Descartes effected a fundamental shift in the relationship between existence and the subject, separating the subject from existential being and subordinating all other modes of being to its autonomy. That is, subjectivity became determinative for existence, and autonomy its normative standard. ${ }^{36}$

Locke later adopted the Cartesian subject as a mode for metaphysically conceiving of the human person. As in the case of the Cartesian subject the Lockean person is characterized by an experiential dimension,

the person is the same if he is aware of himself in different places and different times $[\ldots]^{37}$

which is to say he is self defining. Unlike Descartes' res cogitans, however, Locke's person is neither strictly independent of the body nor one in substance with it and is, therefore, purely epistemological, where the subject is known only experientially by the phenomenal knowledge of its presence. In the Lockean person, metaphysical association with being is never directly linked to an existence that is prior to the experience. The Lockean metaphysical person is therefore loosely, and in cases largely, independent of an entity of the sort that is preeminent in Cartesian thinking.

Significantly, the Cartesian separation of the subject from its material manifestation has also effected a third manner of conceiving of the

${ }^{36}$ Cf. B. Onishi, Information, Bodies, and Heidegger: Tracing Visions of the Posthuman, "Sophia" 50 (2011) issue 1, p. 101-112.

37 Ryan A. Piccirillo, The Lockean Memory Theory of Personal Identity: Definition, Objection, Response, http://www.inquiriesjournal.com/articles/1683/the-lockean-memory-theory-of-personal-identity-definition-objection-response 
relationship between these two metaphysical domains that now dominates current metaphysical approaches to the subject in neuroscience. In this third manner the ontological dependence of the subject rests in an exclusively material order. Historically, the Cartesian emphasis on efficient causality created the materialist conception of reality that dominated Comtean positivism and has since yielded the modern epistemological substitution of fact for ontology. Positivism has been pursued in the neurosciences since the seminal work of Ramon de Cajal with its promotion of the neuron doctrine and a reductionist mechanical operation. 'Cognitive ontology' accounts, for example, thus now view the phenomenal subject as the perceptual realization of a series of neural events. $^{38}$

Though subject to considerable scrutiny and challenge in modern and post-modern philosophy, particularly in its empirical demonstration, both the Cartesian res cogitans and the Lockean person/self yet exert a potent influence on current metaphysical presuppositions that affect the understanding of the individual and the neuroethical praxis that devolves from their conceptions, as does the modern materialist view of reality.

\subsection{Metaphysical Presuppositions and Modern Neuroethics}

Metaphysical presuppositions that influence contemporary normative accounts of the subject extrapolate directly from one of these three metaphysical approaches, or some combination thereof, affecting, thereby, the manner by which value contingency is accorded the neural architecture. Contemporary philosophical currents influenced by the conception of the Cartesian subject include transhumanism and posthumanism $^{39}$. In these trends the autonomy of the isolated subject is normatively privileged, meaning that their chief normative concern is the freedom of willing of the subject ego. Since value is segregated

38 Cf. A. Roskies, Mental Alchemy, op. cit.

39 Cf. N. Bostrom, In Defense of Posthuman Dignity, "Bioethics"19 (2005) no. 3, p. 202-214. 
from the material body, that is, no longer contingent to it, the body can be availed for manipulation according to the demands of the ego. Posthumanist currents, like that of Nick Bostrom, perceive in this value the normative basis for the freedom to refabricate the body and brain according to perceived standards of perfection, one whose reevaluation is ongoing. In consequence, in these understandings the body becomes re-presentable, that is, it is no longer determinative for what is represented, and so no longer an objective reality that constitutively possesses being. In effect, the legitimacy of partial plasticity validates wholesale change, making the body, theoretically and potentially, indefinitely malleable. Independent of the body's unique form, human ontology becomes equated with its description, thereby converting information from an epistemological metric to an ontological resource and depriving being of substance. As Onishi notes:

The technological advancements proposed by transhumanists aim to reduce all material entities to patterns of information in order to have the freedom to arrange and re-arrange them at an anatomical level ${ }^{40}$

Modern philosophies premised on Lockean person, such as extended mind theory (EMT), impersonalism, and ecoethics, for example, while sharing with the res cogitans a primacy of ontology in the conscious and willing subject, are nonetheless distinguished from it by their loose association with the subject's corporal substratum; value contingency is thereby associated with the physical reality of the person but is not confined solely to this locus. By maintaining a metaphysical link between the subject and his corporal reality, the direct manipulation of the body's material order is probative. However, the possibility of invasive intervention in the neural structure is normatively permitted by virtue of the subject's extended and pluralistic associations, which are no longer bound to a single entity. This is due to the dissociation introduced between being and metaphysical entities and being and value that is characteristic

40 Cf. B. Onishi, Information, Bodies, and Heidegger..., op. cit., p. 101-112. 
of the Lockean subject and is adopted in functionalist interpretations of human behavior, like that expressed in Andy Clark's Extended Mind Theory (EMT). ${ }^{41}$ In EMT this instantiation extends to devices that are used to accomplish the same functions that are performed cognitively, that is, the mind is understood to be localized within the set of objects that carry out a cognitive task, rather than just within the brain. Since value contingency is thereby distributed beyond the individual, a position explicitly recognized in Neil Levy's ascription:

If something outside the head plays much the same role in cognition as that within the head, then - given the truth of functionalism - it should be ascribed the same status as it would were it in the head ${ }^{42}$

actions which can permissibly be done on such 'objects' in isolation, hence, are normatively permissible within the brain.

The metaphysical logic of the Lockean subject is hyperbolically extended in Heidegger's deconstruction of metaphysics, which prioritizes being over form. By decoupling the relation between being and human entities the order of value is extended indefinitely to all other objects ${ }^{43}$ thus overcoming the logic of binary subject/object distinctions. By universally extending value contingency, therefore, the central importance of the human being is also negated, that is, anthropocentrism is overcome. The logical trajectory to reductio ad absurdum of value parity between subject and object is seen in Bruno Latour's kingdom of ends ${ }^{44}$ where human value is invested equivalently throughout the whole of the ecological network ${ }^{45}$. Thus, the essential danger of Heidegger's foreclosure of the order of being with form lies in the fulfillment of the

${ }^{41}$ Cf. N. Levy, Neuroethics and the Extended Mind, op. cit., p. 286.

42 Cf. N. Levy, Neuroethics and the Extended Mind, op. cit., p. 292.

43 Cf. G. Rae, Heidegger's Influence on Posthumanism: The Destruction of Metaphysics, Technology, and the Overcoming of Anthropocentrism, "History Human Sciences" 27 (2014) no. 1, p. 51-69.

${ }^{44}$ Cf. B. Latour, We Have Never Been Modern, Cambridge 1993.

45 Cf. D. Chandler, The World of Attachment? The Post-humanist Challenge to Freedom and Necessity, "Millennium Journal of International Studies" 41 (2013) issue 3, p. 516-534. 
metaphysical trajectory begun by Locke, where individuated being is precluded. This has the significant normative consequence of yielding wholly 'impersonalistic' value architectures, an inversion that fully deconstructs anthropocentrism and, ultimately, dematerializes the human entity.

The Cartesian influence that has resulted in materialism, by contrast, has resulted in the mind's loss altogether as an immaterial reality. This reductive and epistemological understanding thus also precludes metaphysical approaches to realist conceptions of the subject as an entity, hence also the possibility of unitary construals governed by integrating principles. In the absence of ontological primacy and broader causal notions the conception of integration can no longer explain physical organization at the progressively complex scales observed in living systems, an approach adopted in neuroessentialism and cognitive ontology.

In neuroessentialism the brain thereby constitutes the sole value contingent object. ${ }^{46}$ Likewise in cognitive ontology, a conception of the human faculties broadly adopted in the neurosciences, such faculties are functionally and collectively interpreted rather than subordinated to a systemic and ontological, coordinating principle. In the absence of such a unitary construal value contingency can neither be centered in the human entity nor is there the possibility of the ontological primacy of the subject in neural operation. In consequence, all organizational arrangements within and beyond the individual share value parity. In praxis, normative parity may, therefore and for example, be extended across a continuum of human machine hybrids, thus ethically permitting their construction at all scales of hierarchy and complexity.

\section{Seeking a Common Metaphysical Platform with Wojtyła's Personalist Subject}

For Wojtyła, the critical dimension of metaphysics situates the ethics of the personalist subject, where the person 'constitutes a privileged

46 Cf. P. Reiner, The Rise in Neuroessentialism, op. cit., p. 165. 
locus for the encounter with being, and hence with metaphysical inquiry'. In the Wojtyłan formulation the normative value of the personalist subject thus emerges from its metaphysical and immaterial mooring, constituting the essential metaethical dimension for neuroethical praxis, and a guarantor of existential perseverance ${ }^{47}$ In other words, by designating the personalist subject a constitutive value locus, Wojtyła is stating that the metaphysical unity of the subject intrinsically determines the manner of acting toward the corporal manifestation, and so grounds his claim against 'dehumanizing' corporal intervention; thus it has a direct bearing on the construction of ethical standards that are probative, that is, the construction of normative statements that pertain to actionable standards that would or would not infringe on a specifically human meaning.

In prevailing models of the subject that are a legacy of Cartesian metaphysics, however, the specifically human meaning of the personalist subject, that flows from his ontological primacy in the order of being, is challenged. As Gillett points out, what is evident in current debates over the nature of material reality is precisely the extent to which the Cartesian imposed segregation of immaterial and material dimensions of reality suffice for ontic adequacy, that is, whether materialism alone or dualism offer adequate explananda to account for the material order. This imposition has repercussions in the ethical sphere. The Cartesian understanding of metaphysics, for one thing, has largely foreclosed a conceptual approach to neuroscience that is linked to entity conceptions, the metaphysical ground that is, a priori, the precondition for the personalist subject. The normative consequences of this foreclosure continue to impact neuroethical praxis and leads, increasingly, to dehumanizing tendencies.

How metaphysics grounds ethical praxis, then, is a critical dimension often ignored in debates about human nature and its modification, that are exacerbated by the advent of neuro and genetic technologies. Human nature is typically conceived in terms of its propertied features alone. This has the normative consequence of severing the individual

47 Cf. N. Clark, Person and Being, op. cit., p. 8. 
as a metaphysical entity from the performative dimensions of his acts. Such division dominates, for example, in perceptual accounts of personhood and human nature such as John Locke's perceptual account of personal identity and its modern derivatives. Indeed, this anthropological conception has been the source of impersonalistic models that deprive the individual of normative value.

Presuppositions invoked in such debates cloud normative conclusions by assigning value contingency exclusively to the material dimension of the individual. They therefore structure debates solely in the context of their epistemic character, which is to say that only the knowledge of the physical world is used to inform its ontological dimension; hence, debates are reduced thereby to valuations of current vs prospective anthropologies, with their corresponding normative assumptions that are solely epistemically framed. Such presuppositions do not account for a physical order that is immaterially informed and metaphysically conceived, a failure that is the basis for ontological inversions that compromise the neuroethical proscriptions they are intended to invoke.

Significantly, while empiricist approaches to epistemology since Descartes have yielded a wealth of detail on the inner workings of natural order, they have offered no conceptual bridge to a realist source of material integration. In a pointed reference to this disarray nobel laureate Robert Laughlin opined both the need and appearance of a new era of synthesis, which he claimed was evidenced in the discovery of the quantum hall effect in $1984{ }^{48}$

The disarray is especially evident in conceptions about the neural architecture and operation, often invoked as the material substrate for the human mind. Mechanists like Carl Craver ${ }^{49}$ and John Bickle, ${ }^{50}$ particularly, remain committed to a world causal order characterized by Bunge's

48 Cf. R. Laughlin, A Different Universe: Reinventing Physics from the Bottom Down, Cambridge 2005 , p. 74.

49 Cf. C. Craver, Physical Law and Explanation in the Hodgkin and Huxley Model of the Action Potential, "Philosophy of Science" 75 (2008) no. 5, p. 1022-1033.

50 Cf. J. Bickle, Reducing Mind to Molecular Pathways: Explicating the Reductionism Implicit in Current Cellular and Molecular Neuroscience, "Synthese" 151 (2006) no. 3, p. 411-434. 
efficient causal sequences and exemplified by Hodgkin Huxley action potential paradigms. Yet, as William Bechtel points out, efficient causal sequences require that formal organizational order be also invoked in explications of dynamical hierarchies, a point argued by emergentists like El Hani on the novel and irreducible properties that make their appearance at successive levels of order ${ }^{51}$ Still others point to the evidence of synthesizing principles that are seen in the dynamic forms of living systems. ${ }^{52}$ The culmination of the multi-staged metaphysical divorce that has transpired since Descartes, however, efficient causal and mechanistic commitments instead drive the prevailing materialism of modern, megascale, neuroscience programs that have recently begun in America (BRAIN), Europe (HBP), and Asia, leaving a decompositional and reductive philosophy to determine how brain operation is interpreted for the foreseeable future. Hence, the presuppositions invoked by these efforts belie the consilience with neuroscience that is more evident in Wojtyta's proposal.

Crucially, the need to account for the emergence of subjectivity from the material order, that is the hallmark of the neural architecture, is left unexplained by the Cartesian metaphysical segregation. In an effort to explicate its emergence philosopher Thomas Nagel ${ }^{53}$ proposes that mind already imbues the natural world, a philosophical concession to the absence of metaphysical explananda for a subjectivity, which is nevertheless evidenced by the material order. The ferment in current efforts to explain the reality of the brain and mind, moreover, indicates that modern metaphysical presuppositions that undergird neuroethics are also in a process of flux. The current uncertainty surrounding the metaphysical status of subjectivity, therefore, suggests that openings to the Wojtyłan metaphysical subject may pass by way of new epistemological revelations on the objective reality of the subjective mind. The conundrum introduced by neuroscience, rather than presenting ob-

${ }^{51}$ Cf. J. Quieroz, C. El Hani, Towards a Multi-Level Approach to the Emergence of Meaning Processes in Living Systems, "Acta Biotheoretica" 54 (2006) no. 3, p. 179-206.

52 Cf. F. Capra, P. L. Luisi, A Systems View of Life, Cambridge 2014, p. 130.

53 Cf. T. Nagel, Mind and Cosmos: Why the Materialist Neo-Darwinian Conception of Nature is Almost Certainly False, Oxford 2012. 
stacles to reconciliation, therefore, may instead confront the Cartesian metaphysical segregation at its root, revealing the material dependence of the neural architecture on an immaterially informed order. Indeed, the epistemological access gained through the neurosciences is itself a revelation not only of an immaterial order but an order grounded in an ontological primacy that is situated in the metaphysical subject, as Wojtyła proposed.

\section{Conclusion}

Numerous neuroethical quandaries today mark concerns over the normative propriety of corporal intervention in the nervous system. At the center of the debates is the question of how the human subject is understood. Accounts influenced by Cartesian metaphysics separate the subject into his immaterial and material manifestations, yielding ethical approaches that devalue the body and the neural architecture. Contemporary neuroscience, on the one hand, proposes that the subject is a purely physiological creation, whereas posthumanism privileges the isolated ego on the other; both, thereby, validate an arbitrary neuroethical praxis. Karol Wojtyła's siting of the personalist subject in a metaphysical structure, where the subject predicates from an ontologically propertied, entity, instead invests the body with value, yielding a principled praxis. In this direct challenge to Cartesian influenced neuroethics, Wojtyła proposes a fundamental corrective to the metaethical principles that ground modern neuroethics; that is, the intrinsic value of the neural and physical reality of the person rests in the link to the metaphysical unity of the immaterial subject, brought into visible reality through its material expression.

\section{Bibliography}

Alon U., An Introduction to Systems Biology, Design Principles of Biological Circuits, Boca Raton 2007.

Bechtel W., Explicating Top-down Causation Using Networks and Dynamics, Oxford 2017. 
Bickle J., Reducing Mind to Molecular Pathways: Explicating the Reductionism Implicit in Current Cellular and Molecular Neuroscience, "Synthese" 151 (2006) no. 3, p. 411-434. Bostrom N., In Defense of Posthuman Dignity, “Bioethics” 19 (2005) no. 3, p. 202-214. Braillard P., Systems Biology and the Mechanistic Framework, "History and Philosophy of the Life Sciences" 32 (2010) no. 1, p. 43-62.

Burgos J. M., The Method of Karol Wojtyła: A Way Between Phenomenology, Personalism and Metaphysics, "Analecta Husserliana” 104 (2009), p. 107-129.

Capra F., Luisi P. L., A Systems View of Life, Cambridge 2014.

Chandler D., The World of Attachment? The Post-humanist Challenge to Freedom and Necessity, “Millennium: Journal of International Studies” 41 (2013) issue 3, p. 516-534. Clark N., Person and Being, Marquette 1993.

Craver C., Physical Law and Explanation in the Hodgkin and Huxley Model of the Action Potential, "Philosophy of Science" 75 (2008) no. 5, p. 1022-1033.

Damasio A., Self Comes to Mind: Constructing the Conscious Brain, New York 2012.

Esfeld M., Quantum Enganglement and a Metaphysics of Relations, "Studies History Philosophy Modern Physics” 35 (2004), p. 601-617.

Friston K., Free Energy and Global Dynamics, in: Principles of Brain Dynamics, eds.

M. I. Rabinovich, K. J. Friston, P. Varona, Boston 2013, p. 261-292.

Gallagher S., How the Body Shapes the Mind, Oxford 2005.

Gillett C., Reduction and Emergence in Science and Philosophy, Cambridge 2016.

Hart Y., Antebi Y., Mayo A., Friedman N., Alon U., Design Principles of Cell Circuits with Paradoxical Components, "Proceedings of the National Academy of Sciences of the United States of America" 109 (2012) no. 21, p. 8346-8351.

Holub G., The Human Subject and its Interiority: Karol Wojtyła and the Crisis in Philosophical Anthropology, "Quien" 4 (2016), p. 47-66.

Hooker C., Interaction and Bio-cognitive Order, "Synthese" 166 (2008), p. 513-546.

John Paul II, Pope, Man and Woman: He Created Them. A Theology of the Body, trans. M. Waldstein, Boston 2006.

John Paul II, Pope, The Splendor of Truth = Veritatis Splendor: Encyclical Letter, Boston 1993.

Kaufman S., The Oigins of Order: Self-Organization and Selection in Evolution, Oxford 1993.

Kelso S., Dynamic Patterns: The Self-Organization of Brain and Behavior, Cambridge 1995. Latour B., We Have Never Been Modern, Cambridge 1993. 
Laughlin R., Physics, Emergence, and the Connectome, „Neuron” 83 (2014) no. 6, p. $1253-1255$.

Levy N., Neuroethics and the Extended Mind, in: The Oxford Handbook of Neuroethics, eds. J. Iles, B. Sahakian, Oxford 2011, p. 285-294.

Maturana H. R., Varela F., De maquinas y seres vivos. Autopoiesis: La organizacion de lo vivo, Santiago de Chile 1979.

Morange M., Les Secrets du Vivant: Contre la Pensee unique en Biologie, Paris 2005.

Moreno A., Mossio M., Biological Autonomy: a Philosophical and Theoretical Enquiry, Berlin 2015.

Onishi B., Information, Bodies, and Heidegger: Ttracing Visions of the Posthuman, "Sophia" 50 (2011) issue 1, p. 101-112.

Paul VI, Pope, Humanae Vitae. Encyclical Letter, Vatican City 1968.

Reiner P., The Rise in Neuroessentialism, in: The Oxford Handbook of Neuroethics, eds. J. Iles, B. Sahakian, Oxford 2011, p. 161-176.

Rae G., Heidegger's Influence on Posthumanism: The Destruction of Metaphysics, Technology, and the Overcoming of Anthropocentrism, "History Human Sciences" 27 (2014) no. 1, p. 51-69.

Roskies A., Mental Alchemy, http://www.theneuroethicsblog.com/2016/08/mental-alchemy_23.html

Smith L., Stability and Flexibility in Development, in: Toward a Unified Theory of Development, eds. J. P. Spencer, M. S. C. Thomas, J. L. McClelland, Oxford 2009.

Toward a Unified Theory of Development, eds. J. P. Spencer, M. S. C. Thomas, J. L. McClelland, Oxford 2009.

Wojtyła K., Man in the Field of Responsibility, Vatican City 1991.

\section{Abstract \\ Framing Neuroethical Praxis: Wojtyła's Metaphysical Subject and its Modernist Cartesian Variants}

Numerous neuroethical quandaries today mark concerns over the normative propriety of corporal intervention in the nervous system. At the center of the debates is the question of how the human subject is understood. Accounts influenced by Cartesian 
metaphysics separate the subject into his immaterial and material manifestations, yielding ethical approaches that devalue the body and neural architecture. Contemporary neuroscience, on the one hand, proposes that the subject is purely a physiological creation, whereas posthumanism privileges the isolated ego on the other; both, thereby, validate an arbitrary neuroethical praxis. By anchoring neuroethics in the metaphysical subject Wojtyła proposes a fundamental corrective to these metaethical approaches, and the promise of a new praxis for corporal intervention in the brain.

\section{Keywords}

Metaphysical subject, neuroethics, bioethics, humanum suppositum, posthumanism, Wojtyła, Heidegger, extended mind theory, integration, theology of the body 